\title{
EDUCAÇÃO AMBIENTAL: UM RELATO DE EXPERIÊNCIA NA COMUNIDADE INDÍGENA ASSURINÍ, MUNICÍPIO DE TUCURUÍ (PA)
}

\author{
Aline Furtado Louzada ${ }^{1}$ \\ Danubya dos Santos Silva² \\ Raiane Contente de Souza ${ }^{3}$ \\ Wendrya Gabriela Alves da Silva ${ }^{4}$
}

Resumo: O objetivo desta pesquisa é relatar as experiências vivenciadas nas ações de resíduos sólidos realizadas pelo Grupo de Estudos em Educação Ambiental (GEA-CAMTUC), projeto de extensão da Universidade Federal do Pará, Campus Tucuruí, na comunidade indígena Assuriní do Trocará, no ano de 2019. O estudo evidenciou que a Educação Ambiental no ensino não formal atrelada aos saberes ambientais indígenas é fundamental para a mitigação de impactos relacionados à saúde e ao saneamento básico, aos quais o povo Assuriní tem sido submetido durante seus processos de deslocamentos.

Palavras-chave: Educação Ambiental; Ensino Não-Formal; Saber Ambiental indígena; Resíduos Sólidos.

Abstract: The research objective is to report the lived experiences in solid waste actions carried out by the Environmental Education Study Group (GEACAMTUC), an extension project from Pará's Federal University, Campus Tucuruí, at the Assuriní do Trocará indigenous community in 2019. The study showed that the Environmental Education in non-formal education linked to indigenous environmental knowledges is a fundamental for the impacts mitigation related to health and basic sanitation, which the Assuriní people have been subjected during their displacement processes.

Keywords: Environmental Education; Non-Formal Education; Environmental Knowledge; Solid Waste.

1 Universidade Federal do Pará, E-mail: alinelouzada@ufpa.br.

2 Engenheira Sanitarista e Ambiental. E-mail: danubyasilva9@gmail.com.

3 Universidade Federal do Pará, E-mail: raiane.souza@tucurui.ufpa.br

${ }_{4}^{4}$ Universidade Federal do Pará, E-mail: wendrya.silva@tucurui.ufpa.br 


\section{Introdução}

A presente pesquisa é resultante da prática de extensão universitária da disciplina Educação Ambiental Participativa da Faculdade de Engenharia Sanitária e Ambiental, que, logo depois, passou a fazer parte do projeto de ações extensionistas do Grupo de estudos em Educação Ambiental (GEACAMTUC), ambos desenvolvidos pela Universidade Federal do Pará (UFPA), Campus Tucuruí. O desenvolvimento das ações foi voltado para o seu públicoalvo, crianças e adolescentes da aldeia Trocará, e objetivou sensibilizá-los, incluindo-os socialmente nas discussões da temática homem-natureza, conforme Dickmann e Carneiro (2012), colocando em foco o saneamento básico e a saúde ambiental através de dinâmicas que evidenciaram suas percepções de seu ambiente, mantendo um aprendizado contínuo entre o educador e o aluno, pois, como indica Freire (1996: 26) apud Silveira e Schiavi (2021: 05), "ensinar inexiste sem aprender."

A pesquisa foi realizada com os indígenas da comunidade Assuriní do Trocará, município de Tucuruí, Estado do Pará, e levantou breves apontamentos sobre os seus saberes ambientais e a sua relação com os resíduos sólidos. Além disso, pretendeu-se ressaltar a importância da Educação Ambiental aliada aos saberes ambientais indígenas como ferramenta transformadora capaz de auxiliá-los na defesa ativa do meio ambiente e na busca constante por seus interesses e direitos sociais e ambientais fora da aldeia em prol do bem-estar dentro da aldeia.

A Reserva Trocará está localizada nos limites de Tucuruí - Baião e cortada transversalmente pela Transcametá (BR 422). De acordo com o Polo Indígena de Tucuruí, a Reserva é constituída de aproximadamente 710 indígenas, distribuídos em quatro aldeias distintas: Trocará; Ororitawa; Oimotawara; e Marawytawa. Dentro da Aldeia Trocará, local das ações, há 645 indígenas, os quais se subdividem em 5 núcleos: Trocarazinho (núcleo composto por famílias da etnia Tembé e Assuriní); Kajwangawa; Toriwaia; Puraké; e Vilinha.

A Reserva Trocará, segundo o site Terras Indígenas do Brasil, possui área de 21.724,38 hectares (Figura 1), tendo sido tradicionalmente ocupada e regularizada pelo Decreto oㅡ 87.845, de 22 de novembro de 1982. Esse não é o local de origem do povo Assuriní; a sua história de ocupação está diretamente relacionada aos conflitos entre povos. No caso, os Assuriní tiveram que se deslocar das terras que dividiam com os Parakanã, na região do Pacajá, para se fixarem nas terras próximas ao rio Tocantins após conflitos entre as etnias (Ribeiro, 2017). Os profissionais técnicos do Polo Indígena de Tucuruí e as lideranças indígenas relatam que a área próxima ao rio Tocantins era farta em caças, como jabutis e tatus, peixes, e tinha solo fértil para o cultivo de roças de mandioca, banana, cará, macaxeira, abóbora e milho na beira do rio. 


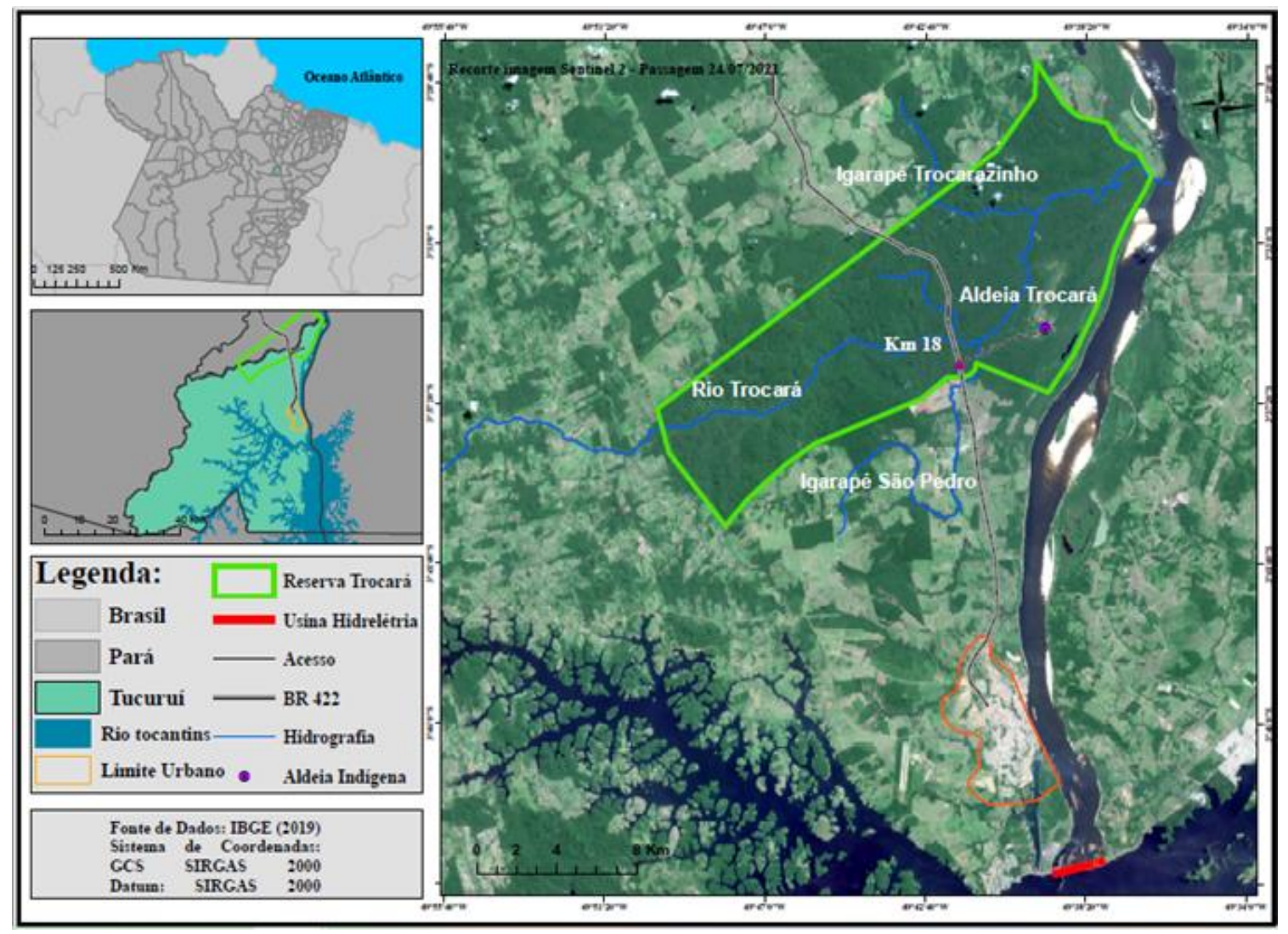

Figura 1: Mapa de localização.

Fonte: autoria própria.

Por consequência da construção da Usina Hidrelétrica de Tucuruí (UHE), a vazão e o enchimento do rio não são mais previsíveis, pois são controlados pela UHE. Isso resultou no alagamento da área de cultivo dos indígenas, que, por sua vez, foram forçados a se deslocar aproximadamente $2 \mathrm{~km}$ adentro da Reserva, ou seja, da beira do rio para a área em que se encontram hoje, alterando drasticamente a dinâmica de produção de seu alimento, além de deixá-los cada vez mais próximos à rodovia Transcametá (BR-422).

$\mathrm{Na}$ época, o contato do povo Assuriní com os não indígenas se restringia ao rio Tocantins, que era sua única via de acesso a Tucuruí, e pelo qual locomoviam-se com canoas para a comercialização de seus produtos. Entre os anos 1982 e 1985, a Reserva foi cortada devido à construção da rodovia Transcametá (BR-422). Essa construção estreitou ainda mais o contato com os não indígenas e com possíveis ameaças ao seu território, como o desmatamento, a queima provocada pela vizinhança e a invasão constante da Reserva por caçadores.

Vale ressaltar também que as perdas territoriais e de recursos naturais acarretaram interferências diretas e/ou indiretas em suas trajetórias. Isso porque, com o deslocamento forçado da beira do rio, os Assuriní perderam 
seus cemitérios por conta do alagamento; esse lugar era considerado sagrado por eles, pois os mantinha em contato com os seus ancestrais.

Por mais que atualmente não exista, na aldeia Trocará, um pajé Assuriní, as práticas ligadas à pajelança continuam existindo, seja por meio do uso de plantas curativas para o tratamento de inúmeras enfermidades, seja pela continuidade dos rituais que correspondem também aos momentos de preparação para que uma pessoa se torne pajé (RIBEIRO, 2020). Esses fatos, mostram, que, apesar das muitas perdas pelas quais os Assuriní passaram, a partir da interação com a realidade na qual estão atualmente inseridos, as suas práticas e os saberes ancestrais continuam resistindo.

O acesso facilitado pela rodovia trouxe riscos tanto à saúde dos indígenas quanto ao meio ambiente, haja vista que propiciou a incorporação de bebidas alcoólicas e de produtos alimentícios industrializados a seus hábitos. Segundo os Assuriní, a introdução desse novo hábito alimentar deve-se ainda ao empobrecimento do solo, resultante do alagamento de sua área de produção agrícola. Na perspectiva de Ribeiro (2017), outro fator que justifica essa entrada de alimentos industrializados é a diminuição dos produtos alimentares, como caças, peixes e frutos nas intermediações da Terra Indígena Trocará, principalmente, por conta das investidas de agentes externos, como madeireiros e caçadores ilegais, que adentram a terra indígena e se apropriam ilegalmente de seus produtos, provocando prejuízos à subsistência dos Assuriní.

Com a introdução de alimentos industrializados na aldeia há também a entrada dos resíduos sólidos, como caixas de papelão, sacos plásticos, garrafas PETs, latas, entre outros. Assim, como esses resíduos não fazem parte da cultura indígena, esse povo teve dificuldade em lidar com essa problemática, assim como nós, não indígenas, temos. A responsabilidade com o meio ambiente sempre fez parte das práticas e da interação cotidiana do povo Assuriní. Por mais que seja observado o descarte incorreto de resíduos sólidos dentro da aldeia Trocará, algumas ações são desenvolvidas pelos profissionais de saúde e de educação que atuam ali dentro, na tentativa de promover a conscientização dos moradores sobre a maneira segundo a qual eles devem proceder com tais resíduos. Por exemplo: gincanas escolares são promovidas pela escola como modo de incentivar a coleta e o descarte do lixo (RIBEIRO, 2017).

Dessa forma, a Educação Ambiental transformadora fundamentada em pensamentos marxistas se mostra aliada da busca por solucionar essa problemática, pois se preocupa com os problemas intrínsecos de cada comunidade, respeitando a cultura local. (LOUREIRO, 2003). O projeto de Educação Ambiental, trabalhado junto com o povo Assuriní, em consonância com os saberes por eles produzidos, buscou fortalecer ainda mais o sentimento de pertencimento e de participação mais ativa da defesa do meio ambiente. 
Desse modo, essa pesquisa tem por objetivo relatar as experiências vivenciadas nas ações de Educação Ambiental realizadas pelo GEA-CAMTUC na comunidade indígena Assuriní do Trocará a partir da temática de resíduos sólidos. Para tanto, a pesquisa pretende buscar a percepção do impacto ambiental ao qual a comunidade tem sido exposta, assim como entender o processo de introdução de resíduos sólidos na aldeia. Para isso, foi necessário analisar os processos de deslocamentos sofridos pelos Assuriní, deslocamentos por conflitos e deslocamentos forçados pelos alagamentos do reservatório da UHE Tucuruí, para, desse modo, identificar como tem sido a articulação do Ministério Público Federal com o grupo tradicional indígena na implementação de medidas mitigadoras de impactos da hidrelétrica sobre a comunidade.

\section{Políticas Públicas no Brasil}

A Educação Ambiental surge de forma conservadora entre as décadas de 1970 e 1980, abordando apenas temas de cunho ambiental dissociados de problemas sociais. Apenas em 1992, com a Rio-92, o Brasil passa a possuir uma Educação Ambiental crítica, pois inserem-se no estudo dessa problemática os movimentos sociais e ambientais, diminuindo a distância entre esses temas (Lima, 2009: 149). Nesse contexto, foram elaborados documentos importantes como a Lei oㅜ 9.795, de 27 de abril de 1999 - Política Nacional de Educação Ambiental (PNEA) -, com propósito de destacar a preocupação social visando a construção "de uma sociedade justa, democrática e sustentável” (LOUREIRO, 2003, p. 47).

No Art. $1^{\circ}$ do capítulo I dessa mesma lei, define-se Educação Ambiental (EA) como

processos por meio dos quais o indivíduo e a coletividade constroem valores sociais, conhecimentos, habilidades, atitudes e competências voltadas para a conservação do meio ambiente, bem de uso comum do povo, essencial à sadia qualidade de vida e sua sustentabilidade (BRASIL, 1999).

A Política Nacional de Gestão Territorial e Ambiental de Terras Indígenas (PNGATI) é responsável por reconhecer e assistir à gestão ambiental e territorial praticada por esses povos em suas terras, trazendo oportunidade para que eles dialoguem com o Estado a fim de elaborar um objetivo comum, para que trabalhem juntos, somando forças, para enfrentar as dificuldades e os desafios que os indígenas brasileiros encaram diariamente. Essa política objetiva assegurar "e promover a proteção, a recuperação, a conservação e o uso sustentável dos recursos naturais das terras e territórios indígenas", de modo que garanta a integridade do patrimônio indígena e uma melhor qualidade de vida, não agredindo autonomia sociocultural desses povos (BRASIL, 2012). 


\section{Educação Ambiental (EA) no ensino não formal}

No processo educativo mais amplo no Brasil, a Constituição Federal de 1988, reconhece o direito de todos à EA e atribui ao Estado o poder de promovê-la em todos os níveis de ensino. A PNEA reforça essas atribuições e institui que a EA deve ser desenvolvida em caráter formal e não-formal. A Educação Ambiental Não-Formal pode ser definida como "ações e práticas educativas voltadas à sensibilização da coletividade sobre as questões ambientais e à sua organização e participação na defesa da qualidade do meio ambiente" (BRASIL, 1999).

A EA é evidenciada por Loureiro (2018, p.3) em caráter político e social e determinada nas seguintes categorias:

Crítica: porquanto funda sua formulação no radical questionamento às condicionantes sociais que geram problemas e conflitos ambientais; Emancipatória: uma vez que visa à autonomia e liberdade dos agentes sociais ante as relações de expropriação, opressão e dominação; e Transformadora: por visar a mais radical transformação do padrão societário dominante, no qual se define a situação de degradação intensiva da natureza, e, em seu interior, da condição humana.

As relações sociais e ecológicas são consideradas intrínsecas quando estão no âmbito da EA crítica e as suas bases éticas e antropológicas fundamentam que a naturalização das relações não é obtida pela opressão ou imposição (PERALTA; RUIZ, 2004 apud COSTA; LOUREIRO, 2017), testificando que as relações sociais submetidas ao capitalismo estão em constante atrito com a natureza e que a ideologia sugere a separação sociedade-natureza. O sistema capitalista impõe a divisão da sociedade em classes sociais, ou seja, se caracteriza pela imposição e pela alienação de uma classe em relação à outra, tornando o contexto social e econômico determinante para o contexto de expropriação e dominação; esses fatores, portanto, podem ser transformados apenas a partir do momento que o sujeito e o grupo social se conscientizem de sua condição de alienação dentro desse sistema (COSTA; LOUREIRO, 2017). Nesse sentido, é possível afirmar que a implantação da UHE e da rodovia advém desse instinto capitalista, que promove uma busca desenfreada pelo lucro e acaba ignorando a relação homem-natureza. Assim, problemas socioambientais são provocados.

Nesse sentido, acredita-se que a Educação Ambiental é determinante para o processo pedagógico (LOUREIRO, 2004, apud BORGES; SILVA; RODRIGUES, 2021) e que essa, quando aliada a ações não-formais críticas e participativas, estimula a transformação das relações dos indivíduos, para que haja uma convivência mais justa e igualitária e para que os sujeitos se tornem agentes sociais atuantes nas questões socioambientais inerentes aos locais 
em que vivem, de forma que busquem políticas públicas que amparem a sua comunidade.

A EA transformadora, fundamentada no pensamento marxista, é aquela que está ligada aos problemas intrínsecos de cada sociedade e que respeita a cultura local, não universalizando os problemas ambientais (LOUREIRO, 2003). Desse modo, estabelecem-se atividades práticas e reflexivas com relação às problemáticas socioambientais da comunidade, conscientizando-a de que soluções sustentáveis podem lhe trazer melhor qualidade de vida.

\section{Metodologia}

O presente artigo é constituído de três fases de pesquisa. Na primeira etapa, foram realizadas pesquisas sobre a temática de $E A$, conceitos e reflexões dos processos de EA com as literaturas de Lima (2009), Loureiro (2003, 2018), Costa e Loureiro (2017), Freire (1996) apud Borges, Silva e Rodrigues (2021).

Para a elaboração da segunda etapa, foram utilizadas as seguintes técnicas para levantamento da realidade socioambiental do local: visitas in loco; aplicação de questionários; ações de Educação Ambiental; e entrevistas on-line via plataforma Google Meet.

O período de vigência do projeto deu-se entre agosto de 2019 e julho de 2020. Em agosto de 2019, o Grupo de Estudos em Educação Ambiental iniciou as pesquisas de campo. Para início das ações na aldeia, foram realizadas visitas ao Polo Indígena, localizado na cidade de Tucuruí, onde foi possível conhecer os profissionais técnicos que atuavam dentro da aldeia. Essas visitas viabilizaram a primeira visita à aldeia, a qual foi autorizada por suas respectivas lideranças e foi acompanhada por integrantes do Polo Indígena.

Para continuação da aproximação com a comunidade, foi proposta uma roda de conversa com os acadêmicos indígenas do curso de Licenciatura Intercultural Indígena da Universidade Estadual do Pará (UEPA). Nesta oportunidade, apresentou-se o cronograma das atividades a serem executadas pelo projeto de Extensão de Educação Ambiental e foi firmada uma parceria entre esses acadêmicos e os integrantes do projeto.

Com intuito de coletar dados para direcionar as ações extensionistas na aldeia, foi aplicado o questionário sobre saneamento básico e saúde ambiental, cuja finalidade foi a de alcançar todas as residências dos cinco núcleos existentes na aldeia Trocará. Para tanto, foram distribuídos 211 formulários; mas obteve-se o retorno de resposta de apenas 30 formulários no período entre junho e agosto de 2019. Mesmo recolhendo um número de formulários preenchidos menor em relação ao esperado, foi possível extrair informações essenciais para o conhecimento da realidade local. 
Para a análise dos dados coletados, foi utilizada a ferramenta Google Forms, com base na pesquisa survey. O questionário era composto de 34 perguntas e dividido em 6 categorias: dados pessoais; identificação do habitat; saneamento; resíduos sólidos; abastecimento de água; e saúde. As ações de resíduos sólidos, que são retratadas neste trabalho, foram direcionadas de acordo com a caracterização da comunidade através do questionário e com a análise aprofundada da categoria de resíduos sólidos.

Devido ao período de pandemia em decorrência da covid-19, em 2020, a continuação da segunda etapa desta pesquisa precisou ser adaptada para entrevistas on-line, via plataforma Google Meet, nos terceiro e quarto bimestres de 2021. Os atores sociais participantes das entrevistas foram uma liderança indígena, Pirá Assuriní; os profissionais técnicos de Endemias e Saneamento do Polo, Djalma Batista e Gileyson Tavares; e Hugo Abas Frazão, Juiz Federal. Em relação a este último, vale ressaltar que, devido ao Código de Ética da Magistratura, o entrevistado não tratou sobre decisões tomadas por outros magistrados ou questões judiciais ainda pendentes de julgamento. A entrevista abordou, portanto, apenas questões gerais a respeito da situação da terra indígena dos Assuriní do Trocará e de sua respectiva comunidade, a fim de verificar o ponto de vista do entrevistado sobre questões jurídicas em geral e de atos judiciais assinados e conduzidos por ele os quais foram considerados relevantes para a pesquisa acadêmica.

Os roteiros das entrevistas foram estruturados em percepções: Percepção de Impacto; Percepção Ambiental (Saberes Ambientais); Medidas Mitigadoras; Envolvimento Social (Audiências Públicas); e Educação Ambiental Crítica e Participativa.

A terceira e última etapa foi dedicada à elaboração do trabalho. Nesse sentido, a presente pesquisa caracteriza-se como sendo do tipo exploratória e descritiva e o enfoque que foi adotado para atender a natureza deste fenômeno é de cunho qualitativo. Conforme Gil (2008), a pesquisa exploratória procura explicitar um dado assunto ou problema pouco conhecido e explorado, por meio de levantamento bibliográfico, de entrevistas com pessoas experientes no problema pesquisado e estabelecendo hipóteses de acordo com 0 conhecimento adquirido pelo explorador. Ainda segundo o autor, as pesquisas descritivas procuram descrever características de uma dada população ou de um fenômeno, ou então estabelecer relações entre variáveis através da utilização de técnicas padronizadas de coleta de dados, como o questionário e a observação sistemática. De acordo com Minayo (2001), a pesquisa qualitativa encarrega-se de responder questões intrínsecas de um determinado assunto ou problema, se preocupando, nas ciências sociais, com um nível de realidade imensurável. 


\section{Resultados e Discussões}

\section{Questionário}

Dentre as respostas obtidas pelo questionário, considerando-se que, no ano de 2019, não existiam serviços de limpeza regular operacionalizados pela prefeitura municipal de Tucuruí na Aldeia Trocará, destacam-se, na categoria de Resíduos Sólidos, as seguintes informações: 28 entrevistados desse quantitativo concordam que essa coleta deveria acontecer regularmente; $63,3 \%$ disseram não separar o lixo seco do orgânico (este é, muitas vezes, aproveitado pelos animais de estimação) e alegaram queimar os resíduos secos, como mostra a imagem do gráfico abaixo (Figura 2).

14. Qual a destinação dada ao lixo gerado na sua residência?

30 respostas
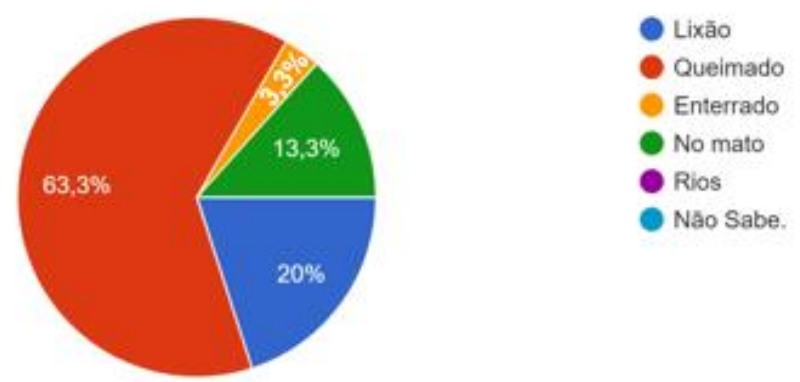

Figura 2: Representação em gráfico da destinação dada ao lixo.

Fonte: autoria própria.

Sabe-se que a atividade de queima de resíduo intensifica a poluição do ar e, consequentemente, ocasiona doenças respiratórias, ou as agrava, no caso da Covid-19, pois um dos seus principais sintomas é a falta de ar. Observou-se também no questionário que $73,3 \%$ disseram que os tipos de resíduos mais gerados na aldeia são o plástico e o papel (23,3\%); esse dado pôde ser confirmado nas visitas técnicas realizadas durante o projeto, em que se constatou que de fato esses são os resíduos mais vistos no local.

Nessas oportunidades, ainda se notou a existência de lixo eletrônico; e $76,7 \%$ do quantitativo afirmou reconhecer esse tipo de lixo com essa nomenclatura. No entanto, $40 \%$ disseram descartar esse resíduo "no mato". Essa prática pode trazer riscos, tanto ao meio ambiente (principalmente ao solo, neste caso), quanto à saúde humana, pois esse tipo de lixo possui substâncias tóxicas, como os metais pesados. 


\section{Ações de Educação Ambiental: Resíduos Sólidos}

As ações de Educação Ambiental, ocorridas no segundo semestre de 2019, foram elaboradas considerando os resultados do formulário e direcionadas de acordo com os estudos de Freire (1996: 85) apud Silveira e Schiavi (2021, p.308), que destaca que o "[...] papel no mundo não é só o de quem constata o que ocorre mas também o de quem intervém como sujeito de ocorrências", sendo a educação uma forma de intervenção no mundo, um aprender para "transformar a realidade, para nela intervir, recriando-a". Assim, atuou-se levando em consideração o contexto sociocultural em que a comunidade está inserida na promoção do respeito, não interferindo em sua cultura e em seu saber ambiental, mas somando os benefícios da Educação Ambiental não formal aos saberes ambientais, como foi no caso dos indígenas Assuriní do Trocará.

\section{Limpeza Ecológica na Aldeia}

Os objetivos desta ação foram a. executar a limpeza da aldeia junto com a comunidade e b. sensibilizar a população a respeito da importância do descarte adequado dos resíduos.

Para essa ação, foi feita uma parceria com a prefeitura municipal de Tucuruí para recolher os resíduos coletados pela comunidade e transportá-los. A ação ocorreu em dois momentos: a. roda de conversa; b. coleta e reconhecimento dos resíduos. Para isso, inicialmente, os pesquisadores reuniram-se com o público-alvo - crianças e adolescentes - para conversar sobre os tipos de resíduos sólidos e sobre a sua durabilidade no meio ambiente. Nesta ocasião, utilizou-se uma apresentação em PowerPoint para ilustrar os exemplos de classificação dos resíduos e o seu tempo de decomposição. Para facilitar o reconhecimento (Figura 3), foram distribuídas luvas a todos os presentes e foi-se "a campo", identificar os tipos de resíduos existentes na aldeia.

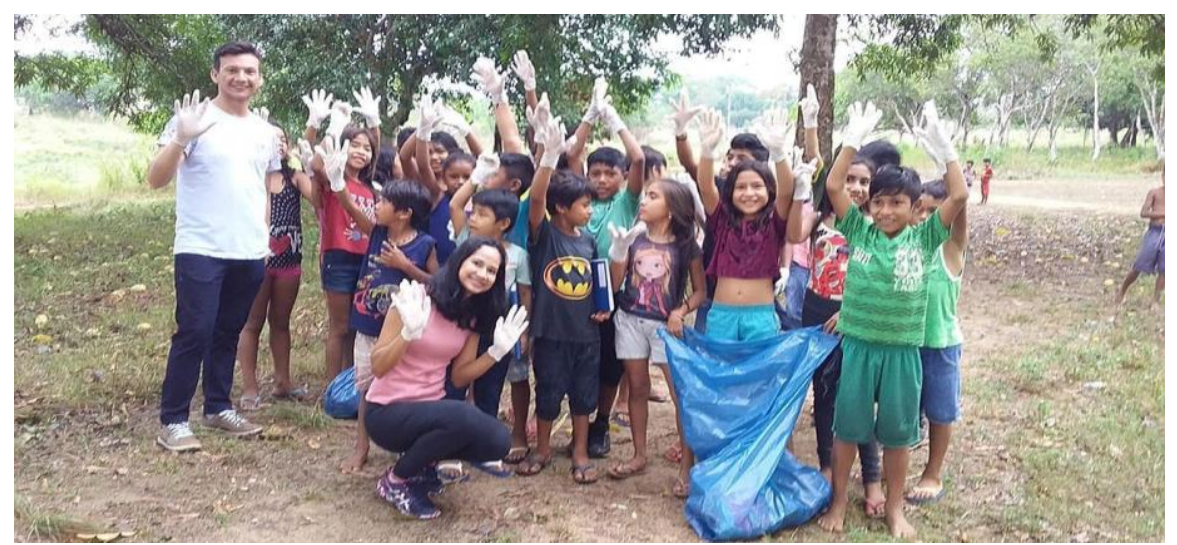

Figura 3: Momento de reconhecimento e coleta dos resíduos.

Fonte: autoria própria. 
No momento da identificação, as crianças e adolescentes eram instigados a classificar aquele resíduo como: papel; plástico; vidro; metal; eletrônicos. Além disso, foi proposto o exercício de lembrar o tempo de decomposição de cada um de acordo com o que fora explanado na roda de conversa.

Entre os resíduos coletados estavam: folha de caderno; embalagem de bombom; garrafa PET; cacos de vidro; latas de sardinha e conserva; pilhas; entre outros. Assim que o resíduo era reconhecido, este era descartado em um saco plástico, para que, após esse momento, fosse feito o recolhimento pelo caminhão da prefeitura.

Durante essa ação de Educação Ambiental crítica e participativa, foi possível despertar a reflexão nos indígenas quanto à demora do processo de decomposição desses resíduos inorgânicos e o quanto o descarte inadequado é danoso, tanto para o meio em que vivem, quanto para a sua saúde e o seu bem-estar.

\section{Saúde e Resíduos Sólidos}

Essa ação teve como objetivo relacionar os riscos que os resíduos sólidos podem trazer para a saúde da comunidade. Assim, buscou-se relacionar a durabilidade dos resíduos inorgânicos e a possibilidade de estes atraírem vetores de doenças contagiosas para o povo Assuriní. Para isso, um vídeo que abordava essa temática foi apresentado; depois, alguns sintomas de doenças como a dengue, a malária, verminoses, febre amarela e leptospirose foram abordados.

Logo depois, a roda de conversa foi aberta para que os pesquisadores pudessem entender a percepção da comunidade por meio de 2 dinâmicas lúdicas e significativas (Figura 4): disputa de quem estoura o balão primeiro dentro do balão havia um papel com perguntas relacionadas aos resíduos e à saúde, que foram temas discutidos na palestra; jogo da memória - neste momento, eles precisavam encontrar o animal e a doença que cada um transmitia.

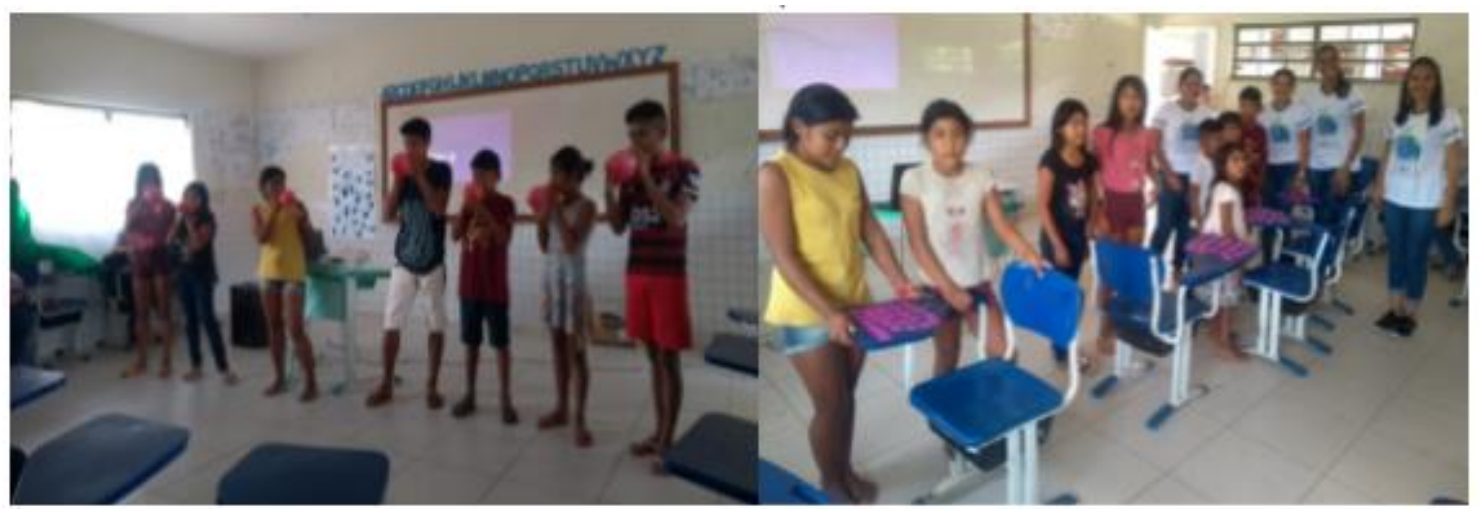

Figura 4: dinâmica dos balões (à esquerda); jogo da memória (à direita).

Fonte: autoria própria. 
Através das dinâmicas foi possível perceber que as crianças e adolescentes mostraram interesse em participar das atividades, o que indica que as metodologias utilizadas são atrativas para eles e estimulam a sua participação e, consequentemente, promovem 0 aprendizado. Os questionamentos levantados durante as dinâmicas foram respondidos corretamente pela maioria dos participantes, demonstrando a assimilação do conteúdo abordado. Além disso, esses interesses se ampliaram quando a abordagem da ação se voltou para as problemáticas e as consequências negativas que o descarte irregular de resíduos sólidos poderia ocasionar para a comunidade, destacando as doenças que ali poderiam ser proliferadas e o comprometimento com a terra que fornece os insumos necessários para a sua subsistência.

\section{Entrevistas Online}

\section{Percepção de Impacto}

Os problemas ambientais que afetam os Assuriní - em vista da intensa relação com não indígenas na região do Trocará, sobretudo com diferentes segmentos sociais que compõem o município de Tucuruí - não são recentes e nem se restringem à internalização de produtos industrializados em sua base alimentar. Mas fazem parte de sua história de contato com diferentes perspectivas em diversos momentos. Na década de 1980, com a construção da UHE de Tucuruí, os impactos ambientais sentidos pelos Assuriní passaram a ser cada vez maiores, transformando a sua realidade e provocando danos irreparáveis a seu território e à população local.

Segundo os dispositivos da Resolução CONAMA no 01/86, define-se impacto ambiental como sendo "qualquer alteração das propriedades físicas, químicas e biológicas do meio ambiente, causada por qualquer forma de matéria ou energia resultante das atividades humanas [...]" (BRASIL, 1986). A construção da UHE Tucuruí produziu, e ainda produz, efeitos sociais diversos sobre a comunidade indígena Assuriní do Trocará, os quais ainda não foram devidamente reconhecidos e mitigados. A percepção de impactos dos agentes sociais envolvidos na pesquisa corrobora essa afirmativa.

Então assim, primeiro a gente tinha muita fartura né, quando construíram a usina aí a gente perdeu muitas coisas. Então é assim, a gente nunca vai recuperar as coisas que a gente perdemos (sic), como castanhal, como a roça, seringal tá e até hoje a gente enfrenta uma dificuldade que tá tendo a erosão. Com essa erosão, ela tá quebrando os barrancos da beira do rio aí vai [...] diminuindo da reserva [...] a gente fica muito preocupado com isso. Antigamente a gente perdemos (sic) a caça também, muita caça, era peixe, jabuti, tatu, o que tinha na reserva que ficava na beira do rio foi tudo perdido. Então assim, essa Usina ela trouxe um impacto pra gente muito, muito 
preocupante e até hoje preocupa a gente quando a gente fez um levantamento com a Eletronorte sobre isso aí, tem coisa que Eletronorte, ela não pagou até hoje, isso vai ficar pra sempre (Pirá Assuriní, Liderança Indígena).

Pirá, em sua fala, lista os danos materiais gerados pela construção da UHE na estrutura social Assuriní, indicando que, com os alagamentos e as perdas de roças e de áreas inteiras de florestas, eles tiveram que se deslocar da região que se fixavam nas proximidades do Tocantins para a região atual. Esse deslocamento provocou rupturas e afetou a subsistência do grupo. Esses fatos mostram as violações sofridas pelos Assuriní; e, em relação a eles, não foram apresentadas medidas eficazes para ressarcir, mesmo que parcialmente, as suas perdas.

Em conversa com o técnico de saneamento do Polo Indígena, ele pontuou em sua narrativa os impactos mais gerais, os efeitos negativos, ocasionados pela construção da UHE. O técnico considerou que esses impactos estavam diretamente ligados aos resíduos sólidos e às consequências que a produção de tais resíduos acarreta para os Assuriní da aldeia Trocará. Como fica perceptível no trecho a seguir:

Os efeitos pós construção...é, são mais referentes a questão dos resíduos sólidos na minha opinião tá... Em relação ao lixo, eles podem atrair vetores que podem trazer problemas, por exemplo, de diarreia. Outra situação é em relação a proliferação do mosquito da dengue né, e outros mosquitos que trazem outras doenças (Gileyson Tavares, Técnico em saneamento do Polo Indígena).

\section{Percepção Ambiental}

"Meio ambiente é o conjunto de condições, leis, influências e interações de ordem física, química e biológica, que permite, abriga e rege a vida em todas as suas formas", de acordo com o Art. 3ㅜ, inciso I, da lei № 6.938, de 31 de Agosto de 1981 (BRASIL, 1981). Além das condições biofísicas, entende-se meio ambiente como sendo as relações socioculturais que são estabelecidas entre as comunidades e os seus ambientes e espaços territoriais.

Nas pesquisas realizadas, observou-se que os Assuriní da aldeia Trocará têm uma forte ligação com o meio ambiente. $O$ cuidado com 0 território, as tentativas de conservação ambiental e a obtenção apenas dos recursos que Ihes são imprescindíveis para a subsistência são fatores que demarcam essa relação com a natureza. Porém, as interferências ambientais diretas, provocadas por agentes externos, ocasionam violações ao modo de vida, à cultura, aos rituais e ao território e são também sentidas por eles. Como fica evidenciado nesta fala: 
A gente tem uma cultura rica também, quer dizer, muitas pessoas lá não falam, eles entende (sic) é... a língua. Agora um espírito como um Pajé, ele tinha um dom de fazer coisa dele lá, nós não temos lá. Atualmente não tem. Então assim, o que nós fazemos, nós cantamos, nós dançamos (Pirá Assuriní, Liderança Indígena).

Para Pirá, são muitas as marcas negativas deixadas pela relação com os não indígenas, os empreendimentos governamentais e as influências urbanas. Essas marcas afetam ainda diretamente o modo segundo o qual as novas gerações exercem as práticas culturais ancestrais de seu povo.

Pela intensidade das relações com a natureza nutrida pelos moradores da aldeia Trocará, os Assuriní têm ciência dos prejuízos causados pela intensificação da produção e pelo descarte irregular de resíduos sólidos dentro da aldeia. Essa preocupação é vista nestes dois recortes da entrevista do Líder Pirá Assuriní. No primeiro relato, ele afirma que a prática de queima do resíduo pode prejudicar o solo; e, no segundo, comenta sobre uma reunião feita com a Eletronorte, em que a empresa, no projeto de saneamento, propôs a implantação de um aterro familiar - buraco impermeável com tampa, escavado no solo para depositar resíduos inorgânicos -; e alguns líderes indígenas foram contra essa proposta.

Já tinha pessoas que juntavam né, lixo e faziam um buraco ali e queimava e agora não pode né, que ele vai prejudicar o solo né, então o jeito é tirar ele de lá de dentro (aldeia), o lixo (Pirá Assuriní, Liderança Indígena).

Teve um índio lá que disse que poderia acontecer uma explosão, quando for aterrar o lixo. E eu fiz uma pergunta pra eles: Quantos anos esse aterro, ele vai durar né, com esse lixo lá dentro? Não, no mínimo é no máximo vai durar cinco anos. Ele é tudo (sic) bem forrado. Pois é, e depois de cinco anos, como é que vai ficar? Então foi por causa disso aí que foi descartado o Aterro Familiar (Pirá Assuriní, Liderança Indígena).

Nas análises das narrativas de Pirá Assuriní, percebe-se que o problema envolvendo o descarte irregular de resíduos sólidos na aldeia Trocará faz parte da agenda debatida pelas lideranças locais. Além disso, percebe-se uma preocupação sobretudo com os efeitos danosos para o meio ambiente e para a sobrevivência das pessoas que compõem a Terra Indígena. Por isso, eles buscam, junto aos órgãos governamentais competentes, alternativas mais eficientes para a destinação dos resíduos, com o fim de evitar danos cada vez mais severos para a população indígena. 
Atualmente, existe uma parceria entre a Prefeitura Municipal de Tucuruí e o Polo Indígena para a coleta semanal dos resíduos na aldeia. De acordo com os relatos, essa ação é a mais aceita pelos indígenas, os quais assumem a responsabilidade de descartar corretamente os resíduos nos dias e horários indicados para a coleta, partindo do entendimento que essa ação é necessária para que não prejudiquem ainda mais o meio ambiente com 0 descarte irregular de resíduos.

Todo final de semana ela (prefeitura) tá indo tirar o lixo de lá e melhorou foi muito né [...] de pouco, de pouco ela tá tirando né, mas é aquela questão quem leva o lixo lá pra dentro somo (sic) a gente mesmo. Que a gente vem pra cidade né, aí a gente compra uma coisa aí pega o saco, mas hoje em dia é o que tá faltando é uma orientação pra comunidade, que era o papel da SESAI (Secretaria Especial de Saúde Indígena) fazer isso e a SESAI não tá fazendo. Então é... é isso que tem que ser feito (Pirá Assuriní, Liderança Indígena).

Ademais, percebe-se a importância da conscientização da população indígena para que esse projeto dê certo. A interação com a cidade e o consumo de produtos industrializados, como ressaltado, são fatores que desencadearam o ingresso efetivo dos resíduos sólidos dentro da terra indígena. Por isso, é necessário que a população seja orientada sobre a melhor maneira de fazer o descarte. As lideranças mostram-se preocupadas a respeito dos intensos danos ambientais e, por conta disso, buscam estratégias para a sua diminuição. Na fala de Pirá, porém, fica expresso que nem sempre essa orientação é feita pelos órgãos responsáveis, cabendo às lideranças buscar alternativas para informar a população.

\section{Saberes Ambientais}

Para Leff et al. (1986 apud Leff 2011, p.311), a reflexão sobre problemas referentes a questões ambientais deve ser incorporada a um saber ambiental, considerando que esse saber transcende as disciplinas científicas. A concepção de uma Educação Ambiental integrada a um saber ambiental se estende além do campo das ciências e se constitui como meio para uma visão ampliada de valores éticos e culturais para a gestão racional do ambiente.

As populações indígenas possuem uma forte ligação com a natureza e os cuidados que ela demanda, por isso geram um saber ambiental próprio. Dessa forma, não há ninguém melhor que os indígenas para reconhecer a importância da bacia e do meio ambiente para o desenvolvimento de suas atividades.

Olha, a preservação da nossa reserva, a gente preserva ele (sic) em geral né, porque lá é um território dos Assuriní, então a gente fizemos (sic) a demarcação da reserva, limpamos o pico, 
aqui na beira do rio é que tá tendo essa erosão. É só na beira do rio aí não tem como fazer, fazer ela parar é porque todo ano vai água tá enchendo é, e causa essa erosão (Pirá Assuriní, Liderança Indígena).

Cientes dos cuidados que devem ser destinados na interação com o meio ambiente, eles estão constantemente realizando tarefas para evitar a violação de seu território, por exemplo, a vigilância contra invasores. Além disso, possuem conhecimento amplo sobre as matas, dentre os quais destacam-se: quais solos são os mais propícios para plantação; em quais partes do rio há peixe; quais vegetações são de uso medicinal; e em quais áreas da mata residem os animais que eles caçam para a sobrevivência.

[...] o remédio caseiro que é mais importante pra gente, porque o remédio do branco não presta. O que presta é nosso. O que saí por aí fazer um remédio bom é remédio caseiro mesmo. [...] Pois é, a nossa atividade que a gente que, a gente faz, a gente faz quase todos. A gente faz a roça, a gente faz a pesca né, a gente faz toda... toda, todas as atividades a gente tá fazendo. A gente caça e pesca, faz farinha né. Tudo isso a gente faz (Pirá Assuriní, Liderança Indígena).

Atualmente, são muitas as mudanças sentidas pelos Assuriní em suas práticas ancestrais, seja em relação aos rituais, na alimentação, na relação com o meio ambiente, seja em relação a outros aspectos. Os próprios saberes ambientais se modificaram, gerando incompreensão por parte dos indígenas sobre a maneira mais adequada de lidar com as alterações pelas quais o solo de seu território passa devido à interferência dos impactos ambientais causados pela construção da UHE. Por exemplo, Pirá destaca que, agora, em alguns casos, eles não conseguem identificar os solos mais férteis para as plantações sem ajuda de um técnico agrícola:

[...] porque, por exemplo, a gente vai fazer uma plantação né, não tem nenhum acompanhamento de um técnico pra acompanhar, pra ver a situação do solo né, se é bom ou se é ruim. Então porque, tem muitas coisas quando a gente planta, não dá né. Ele nasce, depois cresce aí ele morre e nenhum dá o fruto é porque a gente não conhece né o solo (Pirá Assuriní, Liderança Indígena).

Importa destacar ainda que os saberes que regem as vivências dos Assuriní são compartilhados nas relações tecidas na convivência diária. É nesse processo que acontece a transmissão dos elementos que compõem a cultura, a língua Assuriní, os rituais e o saber ambiental: 
[...] o meu pai me ensinou muitas coisas boa (sic), hoje ele não tá né, ele... ele faleceu. Agora é eu que tô na frente né. Então é eu sei dançar, eu sei cantar, eu sei qual é remédio que faz remédio caseiro, remédio pra diarreia né. Então é uma coisa que ele me ensinou e ele me ensinou a falar né, a minha língua que até hoje é pra onde eu vou, eu levo a minha língua né. Eu sou um indígena mesmo que falo. Eu domino a língua. Muitos lá não domina (sic), eles tem um, eles entende né, mas só que eles não falam assim como eu falo né (Pirá Assuriní, Liderança Indígena).

Nesse sentido, percebe-se que a comunidade é munida de vários saberes ambientais e está disposta a somar esses saberes aos saberes técnicos com ações auxiliadas por profissionais da área ambiental para a promoção e a ampliação desses conhecimentos com o fim de promover o bemestar da comunidade e seguir na defesa do meio ambiente.

\section{Medidas Mitigadoras}

Segundo o Instituto Brasileiro de Meio Ambiente dos Recursos Naturais Renováveis (IBAMA, 2010: p. 03), um projeto de mitigação é definido como um conjunto de mecanismos metodológicos capazes de "(i) minimizar e/ou evitar os efeitos difusos negativos dos impactos da atividade licenciada, (ii) evitar o agravamento de impactos identificados e (iii) a ocorrência de novos impactos". E o projeto de compensação como um:

conjunto de procedimentos metodológicos balizadores do financiamento de ações compensatórias de caráter coletivo por parte da empresa licenciada quando, diante de um impacto inevitável, for identificada a interferência sobre a atividade econômica e/ou o quotidiano de determinado grupo social (IBAMA, 2010, p.3)

A instalação da UHE sem a participação da sociedade civil em audiências públicas propiciou o agravamento dos impactos socioambientais, os quais, até o momento, são imensuráveis. Os Assuriní, apesar de todas essas violações, não foram passivos em relação ao processo, sempre estiveram na luta para que os danos sofridos fossem de alguma forma reparados. Até hoje, as suas reivindicações permanecem $e$ as lutas firmadas pelas lideranças indígenas são constantes em prol da reparação, mesmo que parcial, desses danos e do pagamento da indenização que lhes é de direito.

É neste sentido que a Justiça Federal (JF) interveio para a celeridade do processo. A concedente foi prescrita pelos órgãos judiciais a apresentar um projeto de mitigação que, no entanto, foi elaborado sem a participação indígena. 
A gente não participamos (sic) de nenhuma reunião do projeto feito é por isso que a gente apanhou de novo com a Eletronorte, porque quando ela tava (sic), ela fez o saneamento lá, era para ser construído (sic) a coluna de concreto pra fazer as colunas das caixas d'água e não foram feito (sic), foram feito (sic) de madeira né e isso aí, a gente não concorda com isso né, mas é aquela questão que no projeto não pode mexer né, não pode tirar, então fica complicado isso porque não tinha um indígena lá pra tá acompanhando e em nenhum momento eles chegaram e falaram não, vai ser assim, vai ser assim, assim, não foi feito isso (Pirá Assuriní, Liderança Indígena).

Com base em seus saberes ambientais, os Assurinís propuseram modificações para o projeto proposto pela Eletronorte; mas, mesmo assim, muitas de suas reivindicações não foram consideradas.

Depois daquela conversa que a gente tivemos (sic) com eles, eles vieram né, mas diziam, eles falaram que iam mudar o projeto, mas no fim não mudaram, continua o mesmo. Aquela questão, o Aterro familiar que não era para ser feito e foi feito em alguns lugares, foi feito lá e em outros não, porque nós vamos de acordo que tá (sic) na ATA. A gente não disse que ia ser feito né, então a gente descartamo (sic) aquele aterro familiar. Mas assim mesmo eles fizeram pra algumas casa (sic) lá fizeram, mas outras não fizeram, porque eu falei assim: olha, vocês só vão fazer as coisa (sic) que está de acordo aqui na ATA né (Pirá Assuriní, Liderança Indígena).

O termo "aterro familiar" não é encontrado em literaturas com a conceituação dada pela Eletronorte aos indígenas; todavia a Fundação Nacional da Saúde (FUNASA) disponibiliza uma técnica semelhante ao "aterro familiar", encontrada no Manual do agente indígena de saneamento (Brasil, 2008: 111). A técnica de "aterro familiar", medida mitigadora proposta pela Eletronorte para tratar dos resíduos sólidos, mesmo sendo pensada apenas para resíduos inorgânicos, se não passar por uma prévia orientação que indique como necessária a separação de materiais úmidos dos secos pode levar à ocorrência de combustão dos materiais depositados. Assim, conclui-se que essa "solução" se mostra mais viável para aldeias que são mais distantes do perímetro urbano, o que não é o caso da aldeia Trocará.

\section{Envolvimento Social}

\section{Audiências Públicas}

Sabe-se que, a partir de 1986, com as Resoluções CONAMA no 01/86 e $n^{\circ}$ 09/87, a Avaliação de Impacto Ambiental (AIA) passa a ser obrigatória para empreendimentos de grande e médio porte e que as audiências públicas 
passaram a ser imprescindíveis nesse processo como forma de garantir a participação da sociedade civil. Nesse sentido, a realização da audiência pública acontece após a execução do Estudo de Impacto Ambiental (EIA) e da realização do Relatório de Impacto Ambiental (RIMA), bem como de sua apresentação ao órgão ambiental.

A UHE Tucuruí não teve EIA/RIMA, visto que, na época de sua construção, não era uma exigência a utilização de instrumentos de proteção ambiental como acontece hoje. Assim, constata-se que, na ausência de EIA/RIMA, o povo Assuriní, consequentemente, não foi ouvido sobre suas reivindicações, pois não aconteceu qualquer audiência pública para a aprovação da UHE. Logo, a comunidade não teve seus interesses atendidos, sendo impactada sob o ponto de vista ambiental e sociocultural. Essa teoria foi confirmada por todos os atores sociais envolvidos nas entrevistas.

Hugo Abas Frazão, membro do poder judiciário Federal, no cargo de Juiz Federal, ficou encarregado de fazer o processamento e julgamento da causa dos Assuriní do Trocará no ano de 2018. Estudar o caso e conhecer a fundo a história dos Assuriní foram as suas primeiras ações no processo, para que, por meio de uma audiência pública realizada dentro da aldeia, na escola Wararaawa, as reivindicações indígenas fossem ouvidas.

\begin{abstract}
Então toda a comunidade pôde participar, [...] se manifestar, fazendo com que de algum modo, mesmo com que no passado essa oportunidade não tivesse sido dada pelo Estado brasileiro, a justiça federal como Estado brasileiro que é, pudesse dizer "olha, se não foi feito até agora eu acredito que ainda existe a necessidade de isso ser feito, disso acontecer". Então, e tem uma frase da própria procuradora da república que ela diz: essa audiência já é uma grande resposta, já simboliza muito (Hugo Abas Frazão, Juiz Federal).
\end{abstract}

Após a audiência pública do dia 04 de maio de 2018, com a participação da Justiça Federal, do Ministério Público, da comunidade indígena e de atores privados, firmou-se um acordo judicial, por meio do qual houve o reconhecimento de um valor, que, se atualizado corresponde a 10 milhões de reais, que deveria ser entregue em favor da comunidade por meio de políticas públicas e de ações para proveito da comunidade.

Atualmente, como forma de cumprir o acordo judicial, a Eletronorte realiza um projeto de saneamento básico na aldeia. No entanto, este projeto não condiz com a realidade da comunidade indígena, posto que há divergência em relação à percepção de projeto ideal por parte dos indígenas em contraste com os projetos propostos pela empresa privada.

Um exemplo disso é o caso do "aterro familiar" apresentado como solução para a questão dos resíduos sólidos na aldeia. A respeito desse projeto, as lideranças indígenas alertaram para a possibilidade de explosões 
nas terras. Diante disso, entende-se que a empresa não visa o bem-estar da comunidade quando se propõe a realizar esses projetos de saneamento; mas está apenas cumprindo uma ordem judicial. Nesse sentido, é de suma importância que os projetos direcionados a populações indígenas sigam as diretrizes da PNGATI.

\section{Educação Ambiental Crítica e Participativa}

Conforme Loureiro et al. (2003, p.38), a Educação Ambiental pode ser definida como "uma práxis educativa que tem por finalidade a construção de valores, conceitos, habilidades e atitudes capazes de possibilitar 0 entendimento da realidade de vida [...]".

A partir dessa perspectiva, é evidente que os resíduos sólidos não fazem parte da cultura indígena, pois, antes de entrarem em contato com produtos industrializados, eles eram acostumados a "ver" os restos de alimentos sumirem no solo e, da mesma forma, esperavam que isso acontecesse com os novos resíduos inseridos na aldeia; entretanto, esses novos materiais não somem com a mesma rapidez dos orgânicos.

Por isso, as ações de EA voltadas para o caso dos resíduos sólidos mostraram a percepção crítica das crianças diante dessa problemática quando elas desenharam 2 cenários de sua comunidade: 1 . Como ela estava naquele momento (com muitos resíduos); e 2. Como queriam que estivesse (limpa, já com lixeira compondo a paisagem). Esta percepção é exemplificada nos desenhos da Figura 5.

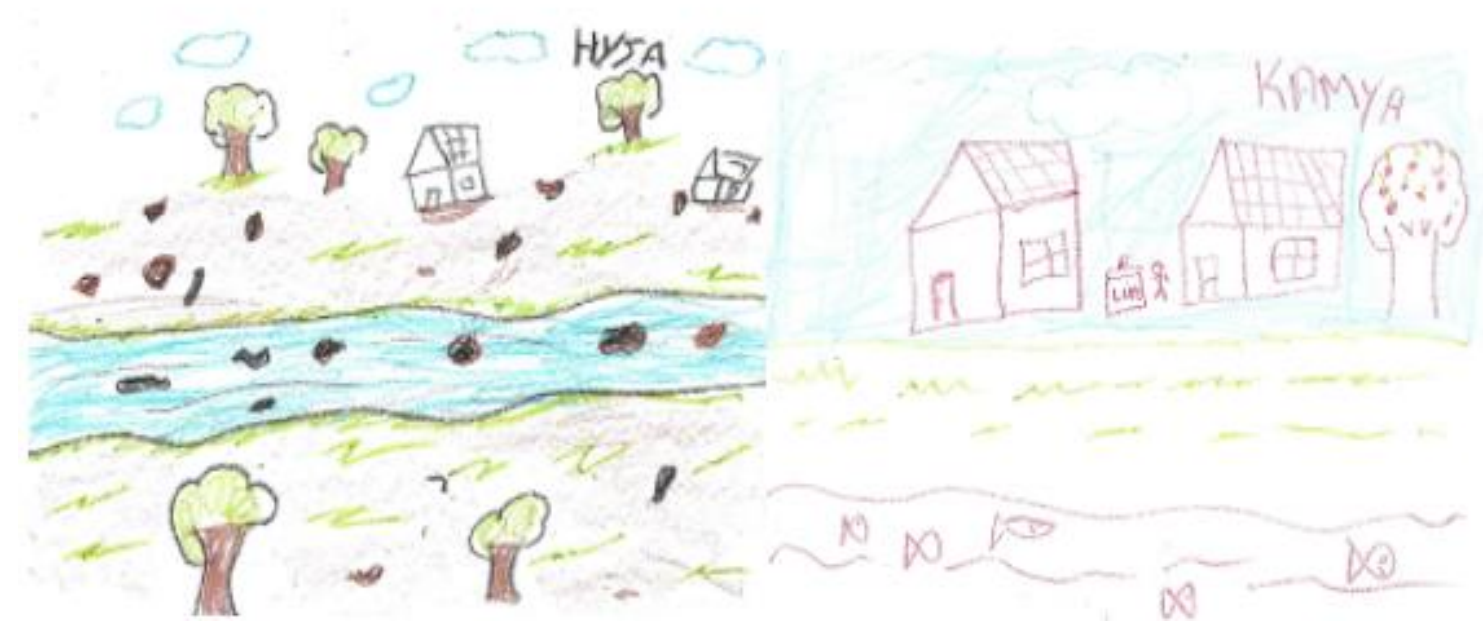

Figura 5: desenho feito por Hysa Assuriní, mostrando os resíduos na Aldeia (à esquerda) e um retrato da aldeia limpa pela Kamya Assuriní (à direita).

Fonte: Arquivo das autoras, 2019.

A primeira expõe, com teor de denúncia, o descaso e os problemas gerados pela irregularidade dos descartes de resíduos sólidos, que afeta as residências e as paisagens da aldeia, o rio e seu próprio modo de vida. No 
segundo desenho, é perceptível a aldeia limpa, com peixes no rio e uma proposta simples, mas eficaz, de incentivo ao descarte correto dos resíduos sólidos. No centro do desenho, uma criança Assuriní depositando o resíduo em um lixeiro fixado entre as residências, o que mostra a conscientização das crianças e uma proposta de intervenção, já que na aldeia não se verifica a existência de lixeiros nos espaços públicos.

Na percepção dos entrevistados, são muito importantes todas as ações desenvolvidas na aldeia que visem à conscientização da população em decorrência da necessidade de se fazer um descarte correto de resíduos sólidos. Por isso, para eles, o projeto de extensão do Grupo de Educação Ambiental foi uma oportunidade de ajudar nesse processo. Essa percepção pode ser analisada nos relatos apresentados a seguir:

O projeto de vocês, ele foi surpreendente entendeu, envolveu bastante as crianças. Acredito que vocês tivessem dado continuidade ao projeto, hoje em dia elas estariam mais participativas, pois elas estariam colocando em prática tudo aquilo que foi repassado, entendeu? Eu acredito que seria bem positivo. Porém eu acho que vocês também deveriam envolver os adultos também [...] Encontrar uma maneira de envolver eles que é difícil. As crianças estão trazendo pro contato com a gente hoje nas visitas já um pouco de entendimento que elas tiveram lá com as ações de vocês, entendeu? A gente não precisa está (sic) indo procurar elas para participar das ações com a gente. Agora elas vêm quando a gente está lá fazendo alguma coisa neste sentido, elas já se aproximam e participam (Gileyson Tavares,Técnico em saneamento do Polo Indígena).

Além de ressaltar a importância do projeto e os efeitos de conscientização e produção de interesses gerados nas crianças Assuriní, esse profissional deu sugestões de expansão do projeto, com o objetivo de garantir uma maior abrangência da população. Na perspectiva do Técnico em Endemias do Polo Indígena, as ações promovidas dentro da aldeia foram positivas para a ampliação do conhecimento de questões ambientais pelos indígenas. Da mesma forma, pontuou-se, em seu relato, a necessidade de continuidade das ações na aldeia.

[...] Na questão de Educação Ambiental, busca de parceiros, nas melhorias, as questões de projetos e ações, é... isso aí eu acho que contribuiu muito e também contribuiu bastante com a vinda de vocês, com a participação de vocês e aí agora haveria um projeto permanente que teria que buscar parceiros pra que esse projeto dê continuidade e que perpetue pra que ele seja implantado [...]. As questões que eu posso contribuir mais é 
que a... no caso o núcleo da... o campus da UFPA é... sempre viesse contribuir em parceria com o polo, com os técnicos do polo né!? pra gente trazer algum trabalho, algumas ações voltada (sic) a essa questão (Djalma Batista, Técnico em Endemias do Polo Indígena).

Para o Juiz Federal Hugo Frazão, o conhecimento produzido sobre a Educação Ambiental leva os indígenas a protegerem os seus recursos e a lutarem por melhores condições de vida:

[...] essa Educação Ambiental eu tô abrindo um pouco -, é dá a comunidade e a seus membros a condição de compreender isso, o local em que eles estão, a posição em que eles estão, a capacidade que eles têm também de reivindicar e buscar - não só dentro do sistema jurídico deles, mas também fora do sistema jurídico que pertence a comunidade indígena - dentro do sistema estatal o reconhecimento da proteção dos seus direitos, isso é o primeiro ponto. [...] uma formação de qualidade é... pode, na minha visão, pode ajudar bastante, assim, todos esses percursos tanto ambiental quanto indígena propriamente dito (Hugo Abas Frazão, Juiz Federal).

Pirá Assuriní valida o apoio de entidades e de grupos que buscam atuar na aldeia para orientar os moradores sobre a importância do cuidado com o solo, sobre a conservação ambiental e a destinação correta dos resíduos sólidos.

A gente queremos (sic) apoio é de umas pessoa (sic) que vai fazer tipo, uma palestra né, é o que tá faltando lá, como cuidar do meio ambiente. Então isso que tá faltando né, tem que ter uma pessoa que tenha conhecimento né, sobre o meio ambiente para tá (sic) explicando lá para fazer a palestra para as pessoas ficarem sabendo das coisas, como é que é... é cuidado do meio ambiente né [...] (Liderança Indígena, Pirá Assuriní).

De acordo com as observações feitas pelos pesquisadores e os relatos dos atores sociais envolvidos, a Educação Ambiental crítica transformadora é bem recebida e incentivada pela comunidade indígena Assuriní do Trocará. Dessa forma, a equipe de extensionistas buscou envolvê-los nas organizações das ações para que eles se sentissem não só participantes, mas também promotores das intervenções.

Essa perspectiva é regida pelo Plano de Gestão Territorial e Ambiental de Terras Indígenas (PGTAs), um instrumento da PNGATI, que busca, junto à 
comunidade indígena, instigar e promover agentes multiplicadores de conhecimento pertencentes à aldeia para que haja uma melhor compreensão das problemáticas pontuadas e uma execução de atividades condizentes com a sua realidade.

\section{Considerações Finais}

Através de visitas, observações e relatos dos atores sociais envolvidos no projeto realizado junto aos Assuriní da aldeia indígena Trocará, contatou-se que os processos de deslocamentos por conflitos e alagamentos impactam direta e indiretamente a Reserva Trocará. Além disso, a construção da rodovia Transcametá promoveu o desmatamento, deixando-a ainda mais vulnerável a invasões de agentes externos. Esses impactos ainda produzem efeitos sociais adversos sobre este povo, os quais ainda não foram devidamente reconhecidos e mitigados.

O processo de deslocamento e a construção da rodovia facilitaram o acesso dos indígenas ao perímetro urbano de Tucuruí. Com isso, o hábito alimentar desse povo foi modificado para uma alimentação mais industrializada. Essa modificação trouxe ainda o problema dos resíduos sólidos, pois o lixo não faz parte da cultura indígena. Eles estavam acostumados com os resíduos orgânicos que passam por um processo de decomposição mais rápido que os inorgânicos e, por isso, têm dificuldade, assim como a sociedade não indígena, de fazer o descarte adequado desses materiais.

O Ministério Público Federal juntamente com o Judiciário Federal, através de um acordo judicial, reconheceu um valor de 10 milhões de reais, que deveria ser entregue à comunidade por meio de políticas públicas - ações em proveito da comunidade. Uma parte desse recurso está sendo aplicada em um projeto de saneamento básico na aldeia. Ainda assim, é de suma importância que haja também a elaboração de projetos de Educação Ambiental amparados nas políticas públicas existentes dando suporte para os órgãos que já executam ações desse cunho, pois a EA se caracteriza como uma ferramenta indispensável para a mitigação de impactos relacionados à saúde e ao saneamento básico.

Outra sugestão seria a instalação de uma minicentral de separação, acondicionamento e destinação de resíduos gerenciada pelos próprios indígenas. Além disso, uma capacitação sobre o gerenciamento desses resíduos, promovida pelo técnico de saneamento do Polo em parceria com a Fundação Nacional do Índio (FUNAI) e/ou ainda por meio da Empresa Júnior Esquadro Projetos e Consultoria, seria benéfica para a comunidade, visto que a ação realizada pela prefeitura de coleta de resíduos semanalmente, por si só, não soluciona a problemática de resíduos sólidos, apenas livra-se superficial e inadequadamente do problema, pois estes materiais serão descartados em lixão a céu aberto. 
Com a instalação de uma minicentral, por outro lado, seria possível a separação, o encaminhamento e a venda dos recicláveis em cooperativas da região. A empresa responsável pela aplicação dessas políticas forneceria recursos ou mecanismos para o transporte desse material até a cooperativa, por exemplo, e os recursos gerados com a venda seriam convertidos em melhorias na infraestrutura do sistema, tornando a alternativa prática, viável e sustentável.

O objetivo macro desta pesquisa foi relatar as experiências vivenciadas nas ações de EA durante o projeto de extensão GEA-CAMTUC na aldeia Trocará em relação à temática de resíduos sólidos. É importante frisar que, durante as ações, ambas as partes, pesquisadoras e público-alvo, tiveram um aprendizado significativo, tendo em vista que se levou em consideração o contexto sociocultural em que a comunidade está inserida, respeitando-o, não interferindo em sua identidade cultural.

Além disso, reconhece-se que, apesar do pequeno impacto que essas ações causam, é necessário intensificar a Educação Ambiental no meio da comunidade, já que esta proporciona um resultado tardio e prescinde de processo continuado. $O$ projeto de extensão se mostra uma alternativa para promover a continuidade desse tipo de intervenção, colocando a Universidade como impulsionadora de mudanças significativas e relevantes para a sociedade.

\section{Agradecimentos}

À Universidade Federal do Pará - UFPA, Campus Tucuruí, pelo apoio ao projeto de extensão; ao Polo Indígena de Tucuruí, pelo suporte técnico; ao povo Assuriní do Trocará, pelo acolhimento e confiança depositada na pesquisa; e ao Juiz Federal, Hugo Abas Frazão, por ter sido solícito em colaborar com este trabalho.

\section{Referências}

BRASIL. Constituição (1988). Constituição da República Federativa do Brasil. Publicada no Diário Oficial da União. Brasília: 1988.

BRASIL. Lei № 6.938, de 31 de Agosto de 1981. Dispõe sobre a Política Nacional do Meio Ambiente, seus fins e mecanismos de formulação e aplicação, e dá outras providências.

Disponível em: $<$ https://www.planalto.gov.br/ccivil 03/leis/l6938.htm>. Acesso em: 25 fev. 2021.

BRASIL. Conselho Nacional do Meio Ambiente (CONAMA). Resolução CONAMA № 001/1986. Dispões sobre critérios básicos e diretrizes gerais para o Relatório de Impacto Ambiental - RIMA. Data da legislação: 03/09/1987. Disponível em: <http://www.mma.gov.br/port/conama/res/res86/res0186.html>. Acesso em: 25 fev. 2021. 
BRASIL. Conselho Nacional do Meio Ambiente (CONAMA). Resolução CONAMA № 009/1987. Dispões sobre audiência pública em licenciamento ambiental. Data da legislação: 23/01/1986. Disponível em: $<$ http://www.mma.gov.br/port/conama/res/res87/res0987.html >. Acesso em: 25 fev. 2021.

BRASIL. Lei 9.795, de 27 de abril de 1999. Dispõe sobre a Educação Ambiental, institui a Política Nacional de Educação Ambiental e dá outras providências.

BRASIL. Fundação Nacional de Saúde. Manual do agente indígena de saneamento. Brasília: Funasa, 2008. Disponível em: $<$ http://www.funasa.gov.br/documents/20182/38564/Manual+do+agente+ind\%C 3\%ADgena+de+saneamento+2008.pdf/cd3e130e-5772-4345-8b0c1252e3ec690c >. Acesso em: 15 mai. 2021.

BRASIL. Decreto № 7.747, de 5 de Junho de 2012. Institui a Política Nacional de Gestão Territorial e Ambiental de Terras Indígenas - PNGATI, e dá outras providências. Disponível em: <http://www.planalto.gov.br/ccivil 03/ ato20112014/2012/decreto/d7747.htm $>$. Acesso em: 25 fev. 2021.

BORGES, L. S.; SILVA, J. B. C.; RODRIGUES, D. S. Educação Ambiental e Cultura Quilombola: entre ausências de políticas públicas e práticas de resistência. Revista Brasileira de Educação Ambiental, São Paulo, v.16, No 1: p. 430-449, 2021.

COSTA, C. A. S.; LOUREIRO, C. F. B. A Interdisciplinaridade em Paulo Freire: aproximações político-pedagógicos para a Educação Ambiental Crítica. Revista Katalysis, v. 20, p. 111-121, 2017.

DICKMANN, I.; CARNEIRO, S. M. M. Paulo Freire e Educação Ambiental: contribuições a partir da obra Pedagogia da Autonomia. R. Educ. Públ. Cuiabá, v. 21, n. 45, p. 87-102, jan./abr. 2012.

FREIRE, P. Pedagogia da autonomia: saberes necessários à prática educativa. São Paulo: Paz e Terra, 1996. 165 p.

GIL, A. C. Métodos e Técnicas em Pesquisa Social. 6. ed. São Paulo: Atlas, 2008.

IBAMA. Nota Técnica no 001/2010/IBAMA/DILIC/CGPEG. Rio de Janeiro, $2010 . \quad$ Disponível em: <http://peabc.ibp.org.br/arquivos/secoes/90 notatecnica\%2001-

10 programasdeeducacaoambiental.pdf>. Acesso em: 25 fev. 2021.

LEFF, E. Complexidade, interdisciplinaridade e saber ambiental. Revista Olhar de professor, Ponta Grossa, v. 14, n. 2, p. 309-335, 2011.

LEFF, E. (Coord.). Los problemas del conocimiento y la perspectiva ambiental del desarrollo. México: Siglo XXI, 1986. 
LIMA, G. F. C. Educação Ambiental crítica: do socioambientalismo às sociedades sustentáveis. Educação e pesquisa, São Paulo, v. 35, n. 1, p. 145163, jan./abr. 2009.

LOUREIRO, C. F. B. Premissas teóricas para uma Educação Ambiental transformadora. Ambiente \& Educação (FURG), Rio Grande, v. 8, p. 37-54, 2003.

LOUREIRO, C. F. B. Crítica ao teoricismo e ao praticismo na Educação Ambiental. In: NETO, A. C.; MACEDO FILHO, F. D; BATISTA, M. S. da S. (Orgs.). Educação Ambiental: caminhos traçados, debates políticos e práticas escolares. Brasília: Liber Livro Editora, 2010

LOUREIRO, C. F. B. et al. Cidadania e meio ambiente: construindo os recursos do amanhã; v. 1. Salvador: Centro de Recursos Ambientais, 2003.

LOUREIRO, C. F. B. Trajetória e fundamentos da Educação Ambiental. São Paulo: Cortez, 2004.

MINAYO, M. C. S. (org.). Pesquisa social: teoria, método e criatividade. 18 ed. Petrópolis: Vozes, 2001.

PERALTA, J; RUIZ, J. Educação popular ambiental. Para uma pedagogia da apropriação do ambiente. In: LEFF, E. (Coord.). A complexidade ambiental. São Paulo: Cortez, 2004. p. 241-280.

RIBEIRO, B. de N. P. Mahíra e os saberes femininos: gênero, educação e religiosidade na comunidade indígena Assurini do Trocará, município de Tucuruí/PA. Dissertação de Mestrado - Programa de Pós-Graduação em Educação e Cultura, Universidade Federal do Pará, Cametá, 2017.

SILVEIRA, A. P.; SCHIAVI, C. S. Educação Ambiental no ensino não-formal: estudo de caso do Projeto Harmonia Consciente. Revista Brasileira de Educação Ambiental, São Paulo, v.16, n. 1, p. 305-325, 2021.

RIBEIRO, B. de N. P. Corpo e pessoa Assuriní: práticas de resguardo na aldeia Trocará. Revista Wamon, v. 5, n. 1, p. 89-102, 2020.

Terra Indígena Trocará. Terras Indígenas no Brasil. Disponível em: $<$ https://terrasindigenas.org.br/pt-br/terras-indigenas/3882>. Acesso: 23 de fevereiro de 2021. 